\title{
AS REUNIÕES DE EQUIPE COMO ELEMENTO FUNDAMENTAL NA ORGANIZAÇÃO DO TRABALHO'
}

\author{
STAFF MEETINGS AS A FUNDAMENTAL ELEMENT IN WORK \\ ORGANIZATION \\ LAS REUNIONES DE EQUIPO COMO ELEMENTO FUNDAMENTAL EN LA \\ ORGANIZACIÓN DEL TRABAJO
}

\author{
Elisiane dos Santos Gomes² \\ Maria Elenir de Oliveira Anselmo² \\ Wilson Danilo Lunardi Filho ${ }^{3}$
}

\begin{abstract}
RESUMO: O presente estudo foi desenvolvido como parte do projeto integrado de pesquisa "Novas formas de organizar o trabalho em saúde: ênfase no trabalho da enfermagem" 3 , no Hospital Universitário Dr. Miguel Riet Corrêa Jr. da Fundação Universidade Federal do Rio Grande. Os objetivos propostos foram os de realizar estudos para constatar a ocorrência, o conteúdo, a periodicidade e a visão dos trabalhadores da enfermagem sobre as reuniões de equipe para, assim, produzir conhecimentos a respeito da importância de sua realização periódica. Foram entrevistados 21 profissionais de enfermagem. Através da análise das entrevistas, emergiram duas grandes categorias: as diferentes visões dos trabalhadores da enfermagem sobre as reuniões de equipe e a dicotomia entre o que a teoria preconiza e o que ocorre, na prática, nas reuniões da equipe de enfermagem
\end{abstract}

PALAVRAS-CHAVE: enfermagem, comunicação, reuniões

\section{INTRODUZINDO O TEMA}

Como pesquisador e bolsistas de Iniciação Científica do Projeto Integrado de Pesquisa Novas Formas de Organizar o Trabalho em Saúde: Ênfase no Trabalho da Enfermagem, principalmente a partir de achados da Dissertação de Mestrado Prazer e Sofrimento no Trabalho: Contribuições ao Processo de Trabalho da Enfermagem (Lunardi Filho, 1995), percebemos a insatisfação manifestada por muitos dos profissionais de enfermagem com a inexistência de reuniões periódicas, em sua unidade, para discutir, planejar e avaliar o trabalho por eles realizado. Sua ocorrência vem se dando, geralmente, quando são detectados problemas que, por sua gravidade e urgência, podem comprometer a realização, ainda que precária, da assistência, não permitindo espaço para o diálogo, sugestões e trocas de experiências, apresentando, na maioria das vezes, um caráter autocrático, depreciativo do trabalho realizado e de intensa cobrança.

Como docente e acadêmicas de enfermagem, vimos, desde há muito tempo, notando a precariedade e, até mesmo, a falta de uma efetiva comunicação, não só dos membros da

\footnotetext{
${ }^{1}$ Projeto Integrado de Pesquisa aprovado pelo CNPq. Apoio FAPERGS

2 Acadêmica do Curso de Enfermagem e Obstetrícia da Fundação Universidade Federal do Rio Grande - FURG. Bolsista de Iniciação Científica do CNPq

${ }^{3}$ Professor Adjunto IV do Departamento de Enfermagem e Obstetrícia da Fundação Universidade Federal do Rio Grande - FURG. Mestre em Administração, Doutor em Enfermagem, Pesquisador do CNPq, Orientador
} 
equipe de enfermagem entre si como entre os demais membros da equipe de saúde. Daí, a nosso ver, parecem decorrer problemas que comprometem o bom andamento do processo de trabalho assistencial. Entre as enfermeiras, percebemos que a comunicação vem ocorrendo, quase que essencialmente, durante as passagens de plantão, sendo estas realizadas de forma rápida, com ênfase na transmissão de informações relativas a pacientes com determinadas solicitações, problemas e particularidades que, supostamente, requeiram cuidados especiais e que exijam um maior controle.

Percebemos, também, que não vem ocorrendo uma comunicação mais eficiente entre o enfermeiro e os auxiliares de enfermagem que fazem parte de sua equipe. Prova disso é que os próprios auxiliares de enfermagem, em determinados locais, recebem e passam o plantão, apenas, entre si. Por outro lado, parece que os cuidados vêm sendo realizados sem planejamento prévio do enfermeiro e sem a participação dos auxiliares. Além disso, parece que o enfermeiro não consegue supervisionar, de forma mais direta e contínua, o trabalho realizado e avaliar o seu resultado. Essas situações, possivelmente, levam a uma falta de controle do tipo, do número e da qualidade dos cuidados prestados, ficando os clientes submetidos a uma assistência considerada rotineira, porém, a nosso ver, passível de ter muitos cuidados necessários e importantes, negligenciados, mesmo aqueles considerados de rotina, por não terem sido planejados e, muitas vezes, nem mesmo tendo sido identificados.

Tais constatações nos levaram a conceber a realização desta pesquisa. Assim, buscamos resgatar, na literatura, a importância da ocorrência de reuniões entre os membros de uma equipe, na tentativa de poder evidenciar a necessidade de sua realização freqüente e periódica, para um bom andamento do trabalho por eles executado. Consideramos que, tanto em um hospital como em qualquer outra instituição, a comunicação entre os membros que compõem suas equipes de trabalho é de extrema importância, por desenvolverem atividades que podem envolver duas ou mais pessoas e que, para isso, precisam comunicar-se para entenderem-se, o que acreditamos poder ser alcançado, por meio do estabelecimento de reuniões freqüentes e periódicas. Para tanto, estabelecemos os objetivos, a seguir especificados.

\section{OBJETIVO GERAL}

- Produzir conhecimentos a respeito da necessidade e importância da realização freqüente e periódica de reuniões entre os membros da equipe de enfermagem para discutir, planejar e avaliar questões pertinentes à organização do ambiente e da prática assistencial, com vistas a alcançar o mais adequado funcionamento possivel da unidade, onde realizam o trabalho, e apresentar um melhor desempenho para prestar uma assistência mais eficiente e eficaz aos clientes.

\section{OBJETIVOS ESPECÍFICOS}

- Realizar estudos para constatar a ocorrência, o conteúdo e a periodicidade das reuniões de equipe;

- Conhecer a percepção dos trabalhadores da enfermagem sobre as reuniões de equipe.

\section{IMPORTÂNCIA DA COMUNICAÇÃO}

Para a manutenção dos padrões de trabalho, o entrosamento entre o enfermeiro e os membros de sua equipe, a elaboração de novas idéias e a obtenção de satisfação pessoal, é essencial uma boa comunicação (Schutt, 1975). Em outras palavras, a comunicação existente em um ambiente de trabalho deve ser eficiente, para que não surjam falhas que possam comprometer o bom andamento do processo de trabalho. Segundo Lunardi Filho, Lunardi e 
Paulitsch (1997, p. 64), "comunicar significa tornar comum a uma ou mais pessoas uma determinada informação ou conjunto de dados com um significado que reduz a incerteza ou aumenta o conhecimento acerca de alguma coisa. Por outro lado, o ato de comunicar não deve ser visto apenas como um processo de transmissão e entendimento de informação, mas, também, como uma maneira de possibilitar o entendimento entre as pessoas".

Existem maneiras consideradas apropriadas, ditadas pela sociedade, para que ocorra a comunicação. O desrespeito a suas normas pode causar sofrimento ou perturbações psicológicas às pessoas e interferir, de forma negativa, na qualidade das relações e do nível de entendimento. Entre as muitas destas regras estabelecidas pela sociedade para que ocorra a boa comunicação, podemos citar a distância física recomendada a ser mantida entre as pessoas, a forma de dirigir-se ao interlocutor, a escolha e determinação do local e do horário adequados, a definição prévia do assunto e dos pontos de pauta, dentre outros.

A comunicação não verbal, também, necessita ser levada em consideração pelo seu valor comunicativo, pois, a maneira pela qual nos portamos, através dos nossos gestos e postura, mesmo quando não nos comunicamos verbalmente, pode determinar o sucesso ou não da comunicação. Concordamos com Daniel (1983, p. 66), quando diz que "ninguém faz enfermagem, nem como arte, nem como ciência, sem ser capaz de comunicar-se eficientemente". Em resposta à questão de como deve ser a comunicação, esta autora afirma que é necessário "comunicar de forma a ajudar na resolução de problemas específicos de cada pessoa. E agir de acordo com o que cada um precisa é corresponder as reais necessidades das pessoas. Não executando ações de forma indiscriminada, casual, arbitrária, mas sim de forma específica a atender as reais necessidades individuais".

É através da comunicação que o ser humano manifesta o que se passa na sua vida interior, transmitindo seus sentimentos, pensamentos, esclarecendo, interagindo e conhecendo o que os outros sentem e pensam e, desta forma, consegue ampliar os seus conhecimentos, tornando-se capaz de transformar a si mesmo e a realidade. De acordo com Lunardi Filho, Lunardi e Paulitsch (1997, p. 63), "a valorização e o aperfeiçoamento da habilidade de comunicarse assumem proporções cada vez mais relevantes, pois seu cultivo e utilização são indispensáveis para a execução de qualquer ação, por mínima que seja e por mais elementar que possa parecer".

Desse modo, podemos afirmar que a comunicação é um processo imprescindível em qualquer organização que vise a realização de ações coordenadas entre os seus diferentes níveis. Sendo assim, para o planejamento do trabalho da equipe de enfermagem, parece-nos de extrema importância a comunicação entre seus membros. Por meio de uma comunicação eficiente, a equipe de enfermagem pode conseguir subsídios para planejar melhor a assistência aos clientes e organizar o ambiente de trabalho para alcançar o mais adequado funcionamento possivel da unidade, garantindo, desta forma, a qualidade da assistência prestada. Assim modo, faz-se mister apresentar nossa concepção do que seja trabalhar em equipe.

\section{O TRABALHO EM EQUIPE}

Uma equipe é um grupo de pessoas que realizam algo juntas, sendo que o que foi realizado por elas não é o que as torna uma equipe, mas sim o fato de terem realizado determinada atividade, conjuntamente. Para algumas pessoas, ser parte de uma equipe pode significar a sua própria sobrevivência, pela possibilidade de camuflar seus fracassos pessoais, enquanto que para outras pode significar a possibilidade de atingir o sucesso (Robbins ; Finley, 1997. p.7). Para Robbins; Finley (1997, p.10) existem certas características que precisam estar presentes em um grupo para ser considerado como uma equipe:

- Seus membros têm um compromisso com as metas e objetivos da equipe;

- Há um interesse de cada membro pelo bem estar dos demais; 
- Seus membros enfrentam os conflitos, ao invés de ignorá-los;

- Seus membros encaram as diferenças de pensamento como algo positivo e, potencialmente, capaz de trazer benefícios à equipe;

- Seus membros sabem ouvir uns aos outros;

- Todos têm iguais possibilidades de expor suas idéias;

- Seus membros não tomam decisões importantes, de forma individual;

- Fazem avaliações periódicas do desempenho em equipe para que todos saibam o que está bom e o que pode e precisa ser alterado;

- A equipe comemora suas realizações.

Em uma equipe, todos podem contribuir com suas idéias e opiniões para a solução de problemas. Essa característica essencial do trabalho em equipe faz com que as chances de êxito na resolução dos problemas sejam maiores. Segundo Stoner (1992, p.27), ao serem solucionados os problemas, coletivamente, as pessoas que contribuíram para a tomada da decisão reúnem melhores condições para avaliá-la e terão maiores possibilidades de conhecer e compreender tanto a decisão tomada quanto os resultados obtidos.

Isso é importante, pois promove o engajamento de todos na implementação das decisões e as chances de falha de comunicação serão muito mais reduzidas. Além disso, quando se discute coletivamente um assunto, têm-se a oportunidade de tratá-lo sob várias abordagens e pontos de vista diferentes, o que possibilita que se reflita melhor sobre o tema e, ainda, que se conheça a percepção dos demais membros da equipe sobre o assunto colocado em discussão.

Prova disso é que, quando surge uma ordem ou norma da chefia sem que os profissionais incumbidos de sua execução tenham sido previamente consultados e esclarecidos, geralmente, verifica-se a ocorrência de dúvidas, indignação, revolta e resistência ao seu cumprimento, mesmo que esta ordem ou norma possa apresentar aspectos bastante positivos.

\section{METODOLOGIA}

Num primeiro momento, buscamos resgatar, na literatura, alguns aspectos com relação a importância das reuniões entre os membros de uma equipe e fatores que podem interferir neste processo, de modo a obtermos um embasamento teórico maior a respeito do assunto, que nos possibilitasse realizar as entrevistas previstas com maior segurança e objetividade.

A partir deste procedimento, passamos à realização de entrevistas semi-estruturadas com profissionais de enfermagem de unidades e turnos distintos de um hospital universitário do município do Rio Grande. As entrevistas foram realizadas, somente após a obtenção do consentimento livre e esclarecido assinado previamente pelos entrevistados. Como forma entendida de ser capaz de garantir a fidedignidade das informações, as entrevistas foram gravadas e transcritas, na íntegra, para posterior análise e interpretação dos dados.

Após serem entrevistados 21 profissionais, demos por encerrada a fase de coleta dos dados, pois as informações obtidas começaram a tornar-se repetitivas, sinalizando sua saturação. Essa decisão foi tomada porque, devido a sua natureza qualitativa, de acordo com Minayo (1997), este tipo de pesquisa não se baseia no critério numérico para garantir sua representatividade, pois a amostragem boa é aquela que possibilita abranger a totalidade do problema investigado. Para manter o sigilo e o anonimato dos respondentes, ao serem apresentados fragmentos de suas falas para ilustrar suas opiniões e pensamentos, foram utilizados nomes de flores, para sua identificação.

\section{ANÁLISE E INTERPRETAÇÃO DOS DADOS}

$\mathrm{Na}$ análise parcial dos dados obtidos, evidenciamos a emergência de duas grandes categorias: as diferentes visões dos trabalhadores da enfermagem sobre as reuniões de 
equipe e a dicotomia entre o que a teoria preconiza e o que ocorre, na prática, nas reuniões da equipe de enfermagem. Estas categorias gerais englobam diferentes aspectos que foram salientados, durante as entrevistas. Dentre eles, podemos citar: a necessidade de reuniões, também, para elogios; o fato das reuniões ocorrerem, apenas, quando surgem problemas que, muitas vezes, mesmo com sua realização, não são satisfatoriamente resolvidos; a falta de incentivo para que as reuniões ocorram periodicamente; os problemas de agendamento, pela existência do senso comum de que sua ocorrência depende, unicamente, da iniciativa das chefias para serem agendadas.

\section{AS DIFERENTES VISÕES DOS TRABALHADORES DA ENFERMAGEM SOBRE AS REUNIÕES DE EQUIPE}

Para Hardingham (2000, p. 10), "os requisitos, benefícios e riscos especiais de equipes são acionados assim que, pelo menos, um objetivo comum exija a reunião de esforços. Isso porque o objetivo ou objetivos precisam ser, igualmente, compreendidos por todos os membros da equipe e os esforços, em conjunto, precisam ser coordenados". Assim, uma das situações que chama a atenção na análise é a diferença de expectativas, entre enfermeiros e auxiliares de enfermagem, com relação à ocorrência, características e propósitos das reuniões.

Entre os auxiliares de enfermagem, as reuniões, quando ocorrem, são percebidas como um espaço destinado, apenas, para resolver problemas emergenciais e não como um momento estabelecido e planejado, em que podem ocorrer discussões, reflexões, manifestações de expectativas, opiniões e sentimentos, promovendo uma maior integração entre os membros da equipe.

Quando tem algum assunto que se precisa discutir, se faz reunião, mas não que elas tenham uma data certa para ocorrer. Quando aparece algum problema que precisa ser resolvido, se faz uma reunião... (Cravo - auxiliar de enfermagem)

Segundo Epstein (1977), nas reuniões, devem ser trazidos assuntos que, se deixados sem solução, contribuem para a ineficiência no trabalho: o médico que não atendeu às regras de assepsia, a enfermeira que age com favoritismo, a auxiliar de enfermagem que está tão aflita com problemas familiares que não consegue falar, polidamente, com ninguém. Esses e outros assuntos, também, precisam ser levados à mesa de reuniões e todos os membros podem contribuir para resolvê-los.

Assim, torna-se de extrema importância que as reuniões ocorram de forma freqüente e periódica, pois mesmo na suposta inexistência de problemas, elas podem ocorrer com o objetivo de dividir e compartilhar com a equipe as responsabilidades pelas decisões tomadas e os méritos pelo alcance de resultados satisfatórios, elogiando o bom andamento do trabalho.

Eu concordo com a reunião periódica porque, mesmo sem problema, deveria ter reunião para te elogiar, também, e não só para detectar problemas. (Margarida auxiliar de enfermagem)

Por meio das reuniões, podem ser trocadas idéias e experiências, tornando-se um espaço para estudos e divulgação de conhecimentos, o que implica crescimento para toda a equipe, melhorando a qualidade do serviço prestado ao cliente.

... se não tem problemas, então, vamos pesquisar alguma coisa referente à nossa unidade... coisas proveitosas, para ti crescer, profissionalmente, para acrescentar conhecimentos... (Margarida - auxiliar de enfermagem) 
Segundo Stoner (1992), a busca coletiva de soluções para problemas aumenta as chances de êxito na sua implementação, ao incluir no processo de tomadas de decisão todas as pessoas envolvidas. Quando as pessoas ajudam a resolver um problema, elas vêem a solução, também, como sua e têm um interesse pessoal em fazer com que ela dê certo. Em outras palavras, é importante que os problemas e soluções sejam compartilhados por todos os membros da equipe, sendo a sua não ocorrência habitual um dos pontos relatados pelos enfermeiros como um entrave fundamental para o bom andamento do processo de trabalho.

... porque, sempre, a gente fica com os assuntos todos. Então, com isso, a enfermeira, também, se sobrecarrega porque a gente toma para si tudo e, na verdade, tinha que fazer as reuniões e deu. (Rosa - enfermeira)

As enfermeiras, ainda, relatam sentir falta de reuniões com os demais colegas de outras unidades, a fim de se manterem integradas com o trabalho da enfermagem de todo o hospital $\mathrm{e}$ não, apenas, da sua unidade. A inexistência de reuniões promovidas pela própria chefia do Serviço de Enfermagem com o grupo de enfermeiros favorece a alienação e a perda do sentido coletivo do trabalho que a enfermagem desenvolve.

Eu acho que o grupo de enfermeiras do hospital poderia se reunir com uma certa periodicidade. Eu acho que seria importante porque, às vezes, a gente fica, completamente, alheia à unidade da colega. (Violeta - enfermeira)

As diferentes visões e expectativas, com relação às reuniões, entre os membros da equipe de enfermagem parecem apontar que, com a sua realização, seria possivel atingir melhor e mais facilmente resultados satisfatórios. Entretanto, mesmo havendo insatisfações manifestadas pelos entrevistados, parece que não têm havido tentativas nem o suficiente empenho de estabelecer um diálogo entre os diferentes níveis hierárquicos na instituição para a construção desse espaço para exteriorizarem seus sentimentos, suas mágoas, opiniões e idéias, propondo mudanças no atual modo de sua realização para que se tornem produtivas e sejam percebidas por todos os membros da equipe como um momento de crescimento pessoal e profissional.

\section{A DICOTOMIA ENTRE O QUE PRECONIZA A TEORIA E O QUE OCORRE, NA PRÁTICA, NAS REUNIÕES DA EQUIPE DE ENFERMAGEM}

De acordo com Hindle (1999), as reuniões podem ser definidas como qualquer encontro entre pessoas, tendo como objetivo a resolução de um problema ou a tomada de uma decisão. Mesmo uma conversa informal entre colegas, no corredor, poderia ser descrita assim. Apesar do conceito contemplar a ocorrência de reuniões informais, as reuniões, normalmente, têm um propósito definido, sintetizado em uma pauta (lista de tópicos) a ser discutida, que é divulgada com certa antecedência. Este autor apresenta que uma das piores partes da preparação de uma reunião é encontrar um horário adequado, que seja compatível com as possibilidades de todos os possiveis participantes. Para isso, deve-se entrar em contato com todas as pessoas que integram a equipe para estabelecer um horário em comum, o que parece ser, freqüentemente, negligenciado.

O que a gente se queixava muito das reuniões é que eram fora do horário e não pagavam hora extra. Então, assim, ficava quase que inviável tu conciliar o horário. Até mesmo... eu trabalho... assim, tenho outro emprego. Então marcavam, geralmente... assim, do meio dia a uma. Daí o pessoal que tinha outro emprego ficava difícil de vim, naquele horário. (Margarida- Auxiliar Enfermagem) 
Além deste cuidado fundamental, Hindle (1999, p. 6) indica mais alguns outros cuidados que devem ser levados em consideração, no momento de preparação de uma reunião:

- O local deve ser, convenientemente, equipado e de tamanho apropriado.

- Documentos de apoio à reunião têm de ser, previamente, enviados para todos os participantes;

- Todos os participantes devem ser informados da data, horário, lugar e objetivos da reunião;

- Todos os participantes devem entender qual deve ser sua contribuição para a reunião;

- Todos os participantes devem ter os objetivos da reunião claros, durante o encontro.

Entretanto, as reuniões da equipe de enfermagem, quando realizadas, parecem não seguir estas recomendações abordadas pela literatura, não havendo, nem mesmo, uma fase de preparação. São agendadas em horário não adequado ou com pouca antecedência e, como podemos perceber pelas falas, a seguir, motivadas por momentos de crise.

Então, no momento em que acontece o problema, para-se tudo, chama-se todo mundo pro posto e se conversa sobre o fato acontecido. Então, é assim que são nossas reuniões. (Jasmim - enfermeira)

Elas não são, assim, programadas. Tá, já fizemos as programadas, mas quando tem algum problema, a gente já tenta reunir o pessoal, no mesmo momento em que surgiu o problema, pra se resolver. (Camélia- enfermeira)

Para o condutor, também, são estabelecidos, de acordo com Hindle (1999), alguns pontos que devem ser levados em consideração para garantir o bom andamento de uma reunião:

- Ser flexível, ao lidar com diferentes tons e estilos dos participantes;

- Ser firme, para manter-se dentro do horário e para lidar com problemas;

- Ter mente aberta e receptiva para ouvir a opinião com a qual não concorda;

- Ser equânime, dando a todos o direito de falar.

- Saber resumir idéias;

Cada participante, também, precisa estar bem informado e conhecer as metas da reunião. Quando realizar intervenções, deverá fazê-las de forma clara e sucinta; deve saber ouvir, demonstrando interesse, no que o outro está falando, não permitindo que preconceitos pessoais ou profissionais bloqueiem sua compreensão de bons argumentos que possam ser feitos, durante a reunião.

Esses são alguns pontos considerados por este autor como importantes para garantir a eficácia e eficiência das reuniões. Porém, através da análise das falas percebemos que não parece haver esta preocupação em observar certas regras que poderiam tornar as reuniões, como vêm sendo realizadas, mais produtivas, evitando a ocorrência dos problemas mais comumente referenciados. Segundo Hardingham (2000, p. 10), os problemas mais comuns, constatados nas reuniões são:

- Pessoas que deveriam estar presentes acabam por ausentarem-se ou atrasarem-se;

- O primeiro item da pauta leva uma eternidade para ser tratado e, portanto, os itens posteriores precisam ser tratados, rapidamente, numa corrida contra o tempo;

- A maioria das pessoas não contribui muito para a discussão;

- As reuniões são utilizadas para resolver problemas pessoais;

- Não existe uma relação entre as ações decididas e a designação dos membros específicos da equipe para cumpri-las.

- Muitas pessoas sentem-se frustradas, irritadas, cansadas ou deprimidas, após as reuniões;

Não, porque é só um blá, blá, blá, porque o que sai na reunião, ali, tu vê que não 
acontece, tu vê que, na reunião, é só, ali, a historinha e tu vê que não acontece. (Crisântemo - Auxiliar de enfermagem)

Porque a gente não via... eu acho, assim, produtividade, naquilo ali, né? Não eram produtivas. Eram boas, no momento, mas não frutificavam, pois os problemas continuavam. (Violeta - enfermeira)

Pode-se perceber, através deste conjunto de depoimentos apresentados, que as reuniões, quando ocorrem, apresentam problemas que poderiam ser evitados, se houvesse um planejamento e preparação prévios. Além disso, parece não existir uma relação entre a ação decidida por todos os membros da equipe, resultando em reuniões que resolvem os problemas, apenas, em teoria, não se concretizando os resultados esperados, na prática.

\section{CONSIDERAÇÕES FINAIS}

As realizarmos este estudo e apresentá-lo, podemos perceber que as reuniões da equipe de enfermagem, no nosso local de pesquisa, quando ocorrem, geralmente, são, apenas, na tentativa de resolver problemas emergenciais não proporcionando um espaço para que ocorram discussões, reflexões, manifestações de expectativas, opiniões e sentimentos, não acontecendo, assim, a necessária troca de idéias e divulgação de conhecimentos. Desta forma, parece não favorecer o crescimento profissional e pessoal dos seus membros e da equipe.

Portanto, existem diversos fatores que parecem contribuir para que as reuniões não sejam satisfatórias, pois são visualizadas sob diferentes óticas entre os membros da equipe de enfermagem, não havendo, contudo, o consenso em relação à importância da sua realização freqüente e periódica. Também, percebemos não haver uma concordância entre a forma como as reuniões são realizadas e o que é proposto pela literatura.

Esperamos, com a realização deste trabalho, conseguir explicitar a importância da realização de reuniões freqüentes e periódicas e que, a partir da divulgação dos seus resultados, haja possibilidades de reflexão, por parte dos profissionais da enfermagem e das instituições onde trabalham, a fim de que possam adequar suas condutas, com o objetivo de propiciar um espaço para que as reuniões ocorram e sejam percebidas como um momento de grande importância, dentro do processo de trabalho da enfermagem, com a oportunidade de trazer grandes contribuições para o processo de trabalho em saúde.

\footnotetext{
ABSTRACT: The present study was developed as part of the Integrated Research Project "New Forms of Health Work Organization: emphasis on nursing work", carried out at the University Hospital of the Rio Grande Federal University. A series of studies were carried out with the objective of identifying the occurrence, content, periodicity and vision of nursing personnel about staff meetings in order to understand the importance of holding periodic meetings. Interviews were carried out with 21 nursing professionals. Data analysis revealed two main categories: differences in vision about staff meetings among nursing personnel and dichotomy between what theory dictates and what truly happens in staff meetings.
}

KEYWORDS: nursing, communication, meetings

RESUMEN: El presente estudio se desarrolló como parte del proyecto integrado de investigación "Nuevas formas de organizar el trabajo en salud: énfasis en el trabajo de enfermería", en el Hospital Universitario Dr. Miguel Riet Corrêa Jr. de la Fundación Universidad Federal de Rio Grande. Los objetivos propuestos fueron los de realizar estudios para constatar la ocurrencia, el contenido, la 
periodicidad y la visión que los trabajadores de enfermería tienen sobre las reuniones de equipo, para así, producir conocimientos respecto a la importancia de realizarlas periódicamente. Se entrevistaron a 21 profesionales de enfermería. A través del análisis de las entrevistas, sobresalieron dos grandes categorías: las diferentes visiones de los trabajadores de enfermería sobre las reuniones de equipo y la dicotomía entre lo que preconiza la teoría y lo que ocurre en la práctica, en las reuniones del equipo de enfermería.

PALABRAS CLAVE: enfermería, comunicación, reuniones

\section{REFERÊNCIAS BIBLIOGRÁFICAS}

DANIEL, L. F. Atitudes interpessoais em enfermagem. São Paulo: EPU, 1983.

EPSTEIN, C. Interação Efetiva na Enfermagem. São Paulo: EPV,1977

HARDINGHAM, A. O trabalho em Equipe. São Paulo: Nobel, 2000

HINDLE, T. Como liderar reuniões? 2. ed. São Paulo: Publifolha,1999

LUNARDI FILHO, W. D. Prazer e Sofrimento no trabalho: contribuições à organização do processo de trabalho da enfermagem. 1995. Dissertação (Mestrado em administração). Faculdade de Ciências Econômicas, Universidade Federal do Rio Grande do Sul, Porto Alegre.

LUNARDI FILHO, W. D.; LUNARDI, G. L.; PAULITSCH, F. da S. A prescrição de enfermagem computadorizada como instrumento de comunicação nas relações multiprofissionais e intra equipe de enfermagem: relato de experiência. Rev. Latinoamericana de Enfermagem, Ribeirão Preto, V. 5, n. 3, p. 63-69, julho 1997.

MINAYO, M. C. S.; DESLANDES, S. L.; NETO, O. C.; GOMES, R. Pesquisa Social: teoria, método e criatividade. Rio de Janeiro: Vozes, 1994

ROBBINS, H.; FINLEY, M. Por que as equipes não funcionam, o que não deu certo e como torná-las criativas e eficientes. 2. ed. São Paulo: Campos, 1997.

SCHUTT, M. Enfermagem e Administração. 2. ed. São Paulo: Pau EPV, 1975.

STONER, A. F. et al. Administração. 5. ed. São Paulo: PHB, 1992. 